\title{
The Psychological Problems and Adjustment of The New Generation of Migrant Workers' Urban Integration from The Perspective of Role Theory
}

\author{
Zhang Zhe ${ }^{1, a,{ }^{*}, \text { Wang Zheng }}{ }^{2, b}$ \\ ${ }^{1}$ Changchun University of Science and Technology, School of law, the department of sociology, \\ Changchun, JiLin, China \\ ${ }^{2}$ Jilin Thousands of Seller Investment Network Technology Co., Ltd., Changchun, JiLin, \\ China \\ a1251742@qq.com, b862538750@qq.com
}

"ZhangZhe, Born in June 1979, Shenyang, Liaoning province, Changchun University of Science and Technology, School of law, the department of sociology, Lecturer, Master, telephone number:13504417076

Key words: New generation of migrant workers, Urban integration, Psychological adjustment

\begin{abstract}
The new generation of migrant workers has become the subject of migrant workers, the new generation of migrant workers in the city into the psychological problems in the process can't be ignored. The new generation of migrant workers in the process of city integration, identity confusion, self-affirmation, inferiority breeding, pessimistic lonely mood growing, deprivation and psychological hatred and so on psychological problems in the new generation of migrant workers has been more and more common. These psychological problems also gradually influence behavior in reality in the new generation of migrant workers, the new generation of migrant workers go-slow, violating the basic order of city and even the destruction of public facilities and other acts also gradually, this is a big risk to build a harmonious society in China. This paper decided to study new generation of migrant workers into the specific psychological problems in the process of city using role theory, and explore the causes of these psychological problems, and put forward the corresponding construction And the solution, make contribution to China's harmonious society construction.
\end{abstract}

\section{角色理论视角下新生代农民工城市融入的心理问题及其调适}

\author{
张喆 $1, \mathrm{a},{ }^{*}$,王正 $2, \mathrm{~b}$ \\ 1 长春理工大学法学院社会学系, 长春, 吉林, 中国 \\ 2 吉林省千商众投网络科技有限公司，长春，吉林，中国 \\ a1251742@qq.com, b862538750@qq.com \\ “张喆, 1979 年 6 月生, 辽宁沈阳, 长春理工大学法学院社会学系, 讲师, 硕士, 联系电话 \\ 13504417076
}

关键词: 新生代农民工; 城市融入; 心理调适

中文摘要. 新生代农民工目前已成为农民工的主体, 新生代农民工在城市融入过程中的心理 问题已不可忽视。新生代农民工在城市融入过程中，身份认同混乱、自我肯定不足，自卑 心理滋生、悲观孤独的情绪日益增长、被剥夺感以及仇视心理等等心理问题已经在新生代 
农民工群体中越来越普遍。这些心理问题也逐渐影响新生代农民工在现实中的行为, 新生 代农民工消极怠工、违反城市基本秩序甚至是破坏公共设施等行为也逐渐显现, 这是我国 建设和谐社会的一大隐患。本文决定运用角色理论来研究新生代农民工在城市融入过程中 的具体心理问题, 同时探究这些心理问题的成因, 并提出相应的建议和解决方法, 为我国 的和谐社会建设事业做出贡献。

\section{1. 引言}

农民工问题一直受到学者关注, 而新生代农民工被单独界定后, 迅速成为学者们新的 研究对象。对比以往的农民工新生代农民工主要有以下特点有: 受教育程度较高、心理预 期较高、融入城市的欲望强烈、心理平衡度差。这些特点使他们极易在盛世融入过程中遭 遇挫折，造成心理问题。因此，研究新生代农民工城市适应中的心理问题极具现实意义。 现有的研究大多是对新生代农民工心理健康水平的调查和影响因素的人系, 但缺少对农民 工融入过程深入的探讨。而从社会化的视角来看, 农民工进城务工的过程可以看作是继续 社会化的过程。因此, 选择角色理论来分析农民工城市适应问题具有极强的可行性。本文 从角色理论出发, 将新生代农民工城市适应看成社会化过程中学习和扮演新角色的过程, 并在此基础上分析其心理问题的成因并提出对策

\section{2. 生代农民工城市融入过程中的心理问题}

\section{1 内心孤独}

新生代农民工离开进城务工, 在一个新的工作生活环境中, 他们急需有人来与其交流。 但在新的环境下，周围没有一个认识的人来实现交际。而且农村与城市之间的文化差异， 生活习惯等等, 都会使得新生代农民工在日常工作生活显得格格不入, 这对于被打上“农民 工”标签的人来说, 很难在这种新的环境中来重新发展开拓自己的交际圈。同时, 新生代农 民工进城务工, 远离了原先生活环境, 与原先的人际交往圈变为脱离或半脱离状态, 这对 于新生代农民工他们来说, 自己的倾诉欲望无法得到缓解, 心理压力也没人来帮助缓解, 内心孤独感逐渐产生。

\section{2 自卑心理滋生}

新生代农民工的自卑心理主要表现在人际交往中, 具体表现为缺乏自信、心神不安、 畏首畏尾。部分新生代农民工存在自卑心理, 他们在城市中的生活现状和城市人的生活现 状产生了强烈的反差, 加剧了他们的自卑心理。新生代农民工的自卑心理与环境的变化及 期望值有关。新生代农民工相对传统农业文明下的农民来说具有较高的综合素质, 大多具 有一定程度的文化知识和技能, 往往不满足于现状, 对自己的未来有着较高的期望。进入 城市后, 他们才发现自身在文化、能力等方面与城市居民的差距, 从而产生对自我的不自 信，对自我肯定不足，从而产生自卑心理。

\section{3 心理压力大, 内心焦虑}

新生代农民工进城务工的初始目的是在城市获得更高的收入, 并致力于在城市获得立 足之地或是新的身份。但在他们来到城市以后, 却发现在城市工作的难度比预想中的要难 很多。在理想与现实的巨大差距的冲击下, 新生代农民工的心理压力加大。新生代农民工 进城务工也背负着家庭的期望, 但在进城后的现状并不能让他们回应家庭的期望。他们迫 切想改变当前的现状, 却又苦于没有能力和机会去做出改变, 内心焦虑感也随之产生。 


\section{4 仇视心理}

新生代农民工渴望获得的更好的工作，获得更高的收入以及希望在城市获得新的身份， 这些都是他们进城前的理想。但在现实生活中，他们发现，他们仍旧只能从事那些最基础 的脏、累、苦的工作并且收入并不高, 而城里人却能每天安稳的坐在办公室从事轻松的有 着跟高的收入工作; 在制度方面, 城里人能够享有各种制度和福利保障, 但是新生代农民 工却极度缺乏制度上的保护，每年农民工讨薪事件频发。新生代农民工在若迫的现状下， 会他们倾向于将客观上的能力不足原因转移到城里人身上, 认为这是城市居民对其的刻意 打压，对城里人的态度也会从最初的向往、羡慕以及敬畏向矮妒、不满、仇视。

\section{3. 生代农民工城市融入过程中心理问题的成因}

\section{1 角色规范模糊}

“城里人” 是对城市人口一个宽泛的称谓, 这也是在二元体制下, 强调了城市人口, 将 其与农村人口割裂开来。但是, “城里人”相对于其他角色难以界定, 它的一般行为方式及 其内在的态度和价值观基础都没有一个特定的标准。当新生代农民工进入城市后，在他们 努力扮演“城里人”这个角色的时候，他们对于一个城里人应该做什么、不应该做什么没有 任何头绪; 他们不知道城里人的生活习惯是怎样的、不知道城里人的行为规则是什么。在 他们做出了一定的行为后, 更没有人来告诉他们他们的行为是否正确。在这种模糊的认知 状态下，新生代农民工扮演“城里人”角色势必失败。

\section{2 缺乏角色扮演的引导机制}

新生代农民工在进入城市后, 进入新的生活环境。他们要在这个新的环境下建立新的 人际交往, 从而有利于他们完成角色学习的过程。但是现实情况却是新生代农民工很难在 公司和社区开始扩展自己的人际交往。由于过高的工作强度和过长的加班时间, 工人们几 乎没有属于自己的业余时间。这样的工作和生活方式导致员工之间的人际关系疏离。而且 他们生活的社区也忽视了对社区中新生代农民工这一群体的关怀, 缺少与他们的互动。在 这样的条件下, 新生代农民工难以完成角色学习的过程。

\section{3 缺乏扮演角色所必要的能力}

新生代农民工相较于老一代农民工有着更高的收教育水平，个人职业技能也更专业， 这就让新生代农民工自进入城市之前自信度过高, 自认为自己能够在城市获得更为理想的 工作和更为优渥的报酬待遇。但在正式进入城市去谋求工作的时候, 他们发现他们所追求 的工作要求要远远高于自身所具备的职业素养和能力。这对于刚进入城市的他们无异于迎 头一击, 重重的打击了他们的自信心。而在与城市人口进行比较的过程中, 发现城市人口 的个人素质和职业技能都强于自身。在这诸多理想与现实的鸿沟的打击下, 新生代农民工 自我肯定信心不足, 自卑心理由此产生。

\section{4. 新生代农民工城市融入过程中心理问题的调适措施}

\section{1 对角色做出明确的规范界定}

新生代农民工在城市融入过程中遇到的最首要的难点在于对“城里人”这个角色 缺乏足 够的、准确的认知和了解, 这也就导致了他们在城市融入的过程中扮演“城里人”这个角色 时没有一个可以为之努力的方向，也不知道到底该怎么做才符合一个“城里人”的行为规范。 可以由民政部门和社会对生活在城市里的人的行为规范做出明确界定, 包括这个社会角色 对应一般行为方式及其内在的态度和价值观基础进行规范。并通过各种传播媒介向新生代 
农民工群体进行传播和普及这中概念, 并在日常的生活工作中对自己的行为进行规范, 改 正自身不好的生活习惯、行为习惯，让自己的表现逐渐向“城里人”这个社会角色靠拢。

\section{2 发挥社区的功能建立角色扮演引导和监督机制}

发挥社区的社会服务和人的社会化功能。这项功能是社区面向社区内的所有居民为他 们提供公益性服务。在面对新生代农民工的问题上, 社区目前并没有很好承担起促进新生 代农民工城市融入的社会责任。因此社区可以适当的面对社区内的新生代农民工提供适当 的公益性服务, 如职业培训、文化休闲的组织等，同时社区在这个过程中可以为提供“城里 人”这一社会角色的行为示范这样可以让新生代农民工切身体会到城市居民在日常生活中所 开展的日常活动和行为习惯及行为方式等。

\section{3 企业社会工作的介入}

企业社工可以为新生代农民工组织多种形式的心理咨询如个案工作、小组工作等等。 同时为陷入心理压力的员工定期组织交流、娱乐活动，在为新生代农民工提供交际渠道的 时候也缓解了他们的心理压力。在定期组织的活动中能将多个有相同问题的人联系到一起, 通过小组互动与方案活动达到个人成长与社会目标的完成, 小组工作通过有目的的团体经 验, 协助个人增进其社会功能, 以及更有效地处理个人、团体或社区的问题, 促进新生代 农民工内部的交流，满足他们的社交需求拓宽他们的人际圈，帮助他们缓解心理压力。

\section{4 提高新生代农民工角色扮演能力}

新生代农民工其自身的能力短板限制了他们在城市中职业角色的转变。通过对新生代 农民工的职业技能培训, 完善他们的知识体系, 提高他们的认知水平, 为他们在城市中获 得更好的工作提供必要的职业技能素养, 为他们在城市中获得其理想中的工作提供了可能 性。同时, 通过广泛宣传心理知识, 社区社工和企业社工的介入, 为新生代农民工提供心 理疏导服务, 帮助他们树立准确的行动目标, 提高他们的心理适应和抗挫折能力, 为他们 在城市中的角色转变提供心理支撑。从心理因素和自身能力素养方面拉进新生代农民工与 城市居民之间的差距, 让他们获得与城里人平等的竞争机会, 帮助他们缓解内心压力。

\section{References}

[1] Wang Chunguang. The relationship between social identity and urban-rural integration of the rural migrants in the new generation [J]. sociological research, 2001, (3): 79-84.

[2] Xu Chuanxin. Identity and influencing factors of the new generation of migrant workers [J]. academic research, 2007, (3): 61-63.

[3] Yan Fengwu. The mental health status of migrant workers in Qigihar city of new Chinese survey [J]. Journal of health psychology, 2011, (8):937-938.

[4] Liu Wenjia. China perspective of new generation of migrant workers' psychological characteristics and Countermeasures of [J]. social research by the "Foxconn incident", 2010, (6):63-67.

[5] Shi Qingxin, Feng Wei. Analysis of the psychological problems of the new generation of migrant workers [J]. Journal of the Party School of Ningxia District, CPC, 2010, (5):94-96.

[6] Guo Lili. Study on the psychological problems of migrant workers in the process of urbanization [D]. Xi'an University Of Architecture And Technology, 2011, (1):86-88.

[7] Characteristics, psychological characteristics and Countermeasures of new generation migrant workers [J]. rural economy and science and technology, 2010, (21): 56.

[8] Wolf Lsuterbach,The measurement of personal[M],Psychloly Rearch,1996.

[9] Kennon M-sheldon,Comparing Differntiation and intergration within personal goal system[M].Department of Psycholoy,1995. 
[10] LR Vartan,Self-Discrepancy Theory and Body Image[D].Personality and Social Psycholoy,2012. 